JUSTYNA LEŚNIEWSKA

Jagiellonian University in Kraków

justyna.lesniewska@uj.edu.pl

FRANÇOIS PICHETTE

Téluq University, Québec

francois.pichette@teluq.ca

\title{
CROSSLINGUISTIC INFLUENCE IN ENGLISH AS THE WEAKER LANGUAGE OF FRENCH-ENGLISH AND POLISH-ENGLISH BILINGUAL CHILDREN
}

Keywords: unbalanced bilingualism, BFLA, crosslinguistic influence, error analysis, weaker language

\begin{abstract}
This study aims to assess the extent of crosslinguistic influence in English as the weaker language of unbalanced bilingual children, and to compare the extent of such influence to that reported in the second language acquisition (SLA) literature. Additionally, by comparing children from different L1 backgrounds, we aim to see if typological distance impacts crosslinguistic influence. We collected elicited speech samples from 16 PolishEnglish and 44 French-English children who have had dual language input from birth, but whose English is weaker mostly because it is absent outside the home environment. The crosslinguistic error rates (an average of 6\%) are lower for our participants than averages found in SLA literature, but still considerably high. Although French- and Polish-dominant children present comparable error profiles, the extent of crosslinguistic influence tends to be greater in the case of French-English bilinguals than for PolishEnglish bilinguals, which may reflect the perceived distance between the languages.
\end{abstract}

\section{Introduction}

The aim of this paper is to assess the extent of crosslinguistic influence in English as the weaker language of unbalanced bilingual children. This section presents 
a review of the literature related to relevant issues of crosslinguistic influence and child bilingualism.

\subsection{BFLA and language imbalance}

The children represent cases of bilingual first language acquisition (BFLA), defined as the development of language in young children who hear two languages spoken to them from birth (e.g. De Houwer 2009), i.e. the onset for both languages is simultaneous. BFLA can thus be distinguished from MFLA (monolingual first language acquisition), in which only one language is acquired, and from ESLA (early second language acquisition), in which the child begins to hear regular input in a second language later than in the first language, but no later than the beginning of literacy-oriented educational activities. De Houwer (2009), for example, places that range between 1.6 and 4 years of age.

It is a well-known fact that a bilingual's command of two languages is hardly ever entirely symmetrical, which is completely understandable, given that bilinguals tend to use their two languages in different domains of life and with different people, a fact that forms the basis of Grosjean's (2016) "complementarity principle". Children tend to develop bilingually with sometimes considerable asymmetries, related to the predominance of one of the languages in the child's environment, which affects the quantity of input and interaction (Lanza 1997; Nicoladis, Genesee 1997; Paradis, Navarro 2003; De Houwer 2007).

The role of language predominance at the societal level and the impact of the quantity of input were well illustrated in a longitudinal case study by Silva-Corvalán (2014) of two English-Spanish bilingual boys, which showed how the changing amount of exposure and use of Spanish over the first years of the boys' lives affected their proficiency in Spanish. It is important to note that the pattern of dominance may change, sometimes even several times, during a bilingual person's life (Aronin, Singleton 2012; Flores 2015).

Language dominance is differently operationalized across studies (see e.g. Nicoladis 2016 and Unsworth 2016 for recent discussions), usually in terms of language proficiency, based on a range of performance-based measures such as MLU (mean length of utterance). Recent approaches to language dominance include measurements based on lexical diversity (Treffers-Daller, Korybski 2016). Alternatively, various experiential variables may be used (e.g. Döpke 1992; Argyri, Sorace 2007; Foroodi-Nejad, Paradis 2009). In this paper we adopt what Unsworth calls the "narrow" definition of dominance, i.e. relative dominance, according to which "children's relative proficiency in their two languages is in some sense a function of the amount of language to which they are exposed in those languages" (Unsworth 2016: 156).

Not many studies focus specifically on the less developed language of a bilingual's two languages. The few existing studies (e.g. Meisel 2007; Bonnesen 2009) use the term "weaker language" to refer to such a language. This is also the term we adopt in this paper (abbreviated to $\mathrm{WL}$ ); for the dominant language, we will use the abbreviation SL (stronger language). 


\subsection{Crosslinguistic influence and errors}

Crosslinguistic influence is a major factor in SLA. Defined as "the influence of a person's knowledge of one language on that person's knowledge and use of another language" (Jarvis, Pavlenko 2007: 1), it is known to have a noticeable impact on the acquisition and use of a second language at the levels of phonology, morphology, syntax, lexis, semantics, and pragmatics.

While the most evident traces of crosslinguistic influence reside in the errors that bilingual language users make, the extent of crosslinguistic influence is much greater than just the production of non-target forms. Most importantly, crosslinguistic similarity may have a facilitative effect, a phenomenon which is sometimes referred to as "positive transfer". Also, crosslinguistic influence, even when it is not facilitative, does not necessarily result in errors. The influence may be covert, as is the case when some forms (not necessarily incorrect) are overused or underused in one language due to the influence of another language. Since it is not feasible to explore all the aspects of crosslinguistic influence, in this paper we focus solely on errors and try to establish to what extent they are caused by crosslinguistic influence. Even if errors are not the only manifestation of crosslinguistic influence, it is generally recognized that they provide a window into the nature of bilingual language acquisition (Döpke 2000a), and about language faculty in general (Francis 2011). In a recent compilation of 34 ESL studies in which the percentage of L1-based errors was provided (Pichette, Leśniewska 2018), the average percentage of crosslinguistic errors stands at 42 percent.

\subsection{Crosslinguistic influence in $B F L A$, language dominance, and language distance}

On the basis of the literature, one can expect the SL to affect the WL more than the other way round, since language dominance has been found to impact crosslinguistic influence (Yip, Matthews 2000, 2007; Kupisch 2007). On the other hand, the literature on BFLA suggests that there should be relatively little (or no) crosslinguistic influence in the case of children who have dual language input from birth, as opposed to when language acquisition begins at a later age. For example, De Houwer (2009: 48) argues that, while uneven development of a bilingual's two languages is the norm rather than an exception, "young bilingual children can speak each of their languages without noticeable systematic influence from the other", a fact that she explains by means of the "Separate Development Hypothesis" (SDH). ${ }^{1}$ De Houwer (2009: 48) also notes that while BFLA children may lag behind MFLA children in their "weaker" language, on the whole, "BFLA children resemble MFLA children more than ESLA children in the kinds of things they say".

However, some studies with bilingual children (Hulk 2000; Matras 2009; Leśniewska, Pichette 2013; Leśniewska, Witalisz 2013) have provided evidence that the syntactic systems of both languages affect each other, and that, if there is certain similarity between the two language systems, crosslinguistic influence is more likely to occur (Döpke 20oob; Hulk, Müller 200o).

1 For a list of studies which support the SDH, see De Houwer (2009). 
Regarding language distance, it has been postulated for a long time that the likelihood of a form being transferred depends on the perceived distance between the languages in presence (Kellerman 1983; Ringbom 1987). If speakers perceive two languages as being sufficiently closely related (which may or may not correspond accurately to the actual typological distance), they are more likely to transfer forms from one language to another. Despite the fact that English, French and Polish all belong to different language groups (Germanic, Romance, and Slavic), the degree of similarity between English and French is much greater than between English and Polish, due to the extensive overlap in the lexicons of English and French. In fact, English shares about 25,000 cognates with French (LeBlanc, Séguin 1995), but only about 3,00o with Polish (Otwinowska-Kasztelanic 2010) and in the latter case, a large part of such cognates consists of technical terminology.

This suggests that more transfer should be observed in the language production of French-English bilinguals than Polish-English bilinguals, all other things being equal.

\section{Objectives}

The present study aims at assessing the extent of crosslinguistic influence in the WL production of bilingual children, as manifested in errors. We intend to identify errors in the WL production of bilingual children and compare error profiles of children whose SLs are different, to shed more light on the nature of crosslinguistic influence.

\section{Method}

\subsection{Participants}

Participants were 16 Polish-speaking and 44 French-speaking children aged 4 to 12. The basic criterion for inclusion in the study was being a simultaneous bilingual (that is, with dual language input from birth), and speaking English as a weaker language. The mean age for the Polish-speakers was 6.3 and for the Canadians 7.1. By sheer coincidence, without controlling for gender in the recruitment process, the numbers of boys and girls were equivalent in each group, with 22 boys and 22 girls in Canada, and eight children of each gender in Poland. There were many similarities among our participants in terms of their language development and input patterns (but none of these characteristics served as a selection criterion for the study). Most importantly, all but two of our participants had dual language input form birth due to the fact that one of their parents was a native speaker of English, or an English-French bilingual. Another shared characteristic was that all the parents attributed the fact that Polish/French was their children's stronger language to the prevalence of that language in the children's lives.

Typically, the children's use of English was limited to three contexts: 1) home, 2) English language classes, 3) sporadic interaction with English-speaking relatives 
(e.g. holiday visits). All the participants also read English-language books or watched television or films in English. In both groups there were children whose pattern of language dominance had changed since birth: in some cases, the English language was originally the stronger language, especially in the earliest stages of language production: six of the 16 Polish participants reportedly uttered their first words in English, and this was also the case for 13 of the French-speaking children. Some of the children (both Polish and Canadian) initially lived in an English-speaking country or province, and only moved to their current location at some point. All of the participants, however, eventually developed Polish/French language dominance as a result of living in Poland or Quebec.

Although comparing groups of equal size is always preferable, we had to settle for a lower number of Polish participants, due to the fact that families who live in Poland and in which children have dual (English and Polish) language input from birth are rare and scattered, making them a challenge to find.

\subsection{Procedure and tests}

The fact that English was the WL for all participants was established on the basis of two indicators:

1. Questionnaire data. The participants' parents filled out questionnaires which required them to indicate observed language dominance.

2. Scores on vocabulary tests:

- For English (both groups): participants were administered the Peabody Picture Vocabulary Test (Dunn, Dunn 2007). This 228-item instrument requires the child, upon hearing an English word, to indicate which of four images represents that word.

- For French: The French adaptation of the Peabody test (Dunn, ThériaultWhalen, Dunn 1993) was used with participants in Quebec.

- For Polish: The Polish participants took a vocabulary test based on the same principles as the Peabody (Haman et al. 2012). However, two participants were too old for the age brackets (2.00-6.11) for which the test is intended. For them, we had to rely on the questionnaire data only.

The questionnaires also included several questions concerning the history of the child's language development and language input patterns. These answers yielded additional information on our participants, which was summed up above.

Recording samples of completely spontaneous speech may yield material which is not easily comparable across participants. For that reason, a tool was designed to trigger language production on a specific topic, in the form of three wordless cartoons to describe. Those samples of elicited speech were recorded and transcribed. The main advantage of having all the participants describe the same stories is that the output is similar in terms of topic, which makes various comparisons of the lexical and grammatical features of the output more valid. 
In summary, we collected:

1. Consent forms (from the participants' parents);

2. Questionnaire data (from the participants' parents);

3. Scores on vocabulary tests (with exceptions, as explained above);

4. Elicited speech (a task which involved describing three wordless cartoons).

The vocabulary in each language took about 12 to 15 minutes to complete, since tests are not administered in their entirety; the test is stopped when the child reaches a pre-specified number of error-to-item ratio. The speech elicitation task took an average of 5.5 minutes. Overall testing time revolved around 30 minutes, and the whole procedure was administered individually to each child at home.

\subsection{Error analysis and classification}

The recorded elicitation tasks were transcribed and analyzed independently by two examiners. We considered an error any element of lexical, morphological or syntactic nature that is different from the expected language production of a native speaker. We treated forms which can be found in colloquial English as acceptable ("I think no", "a guy that was", or "there's four ducks"), even if they are incorrect from a normative point of view. As pronunciation-related aspects of our participants' speech were beyond the scope of this investigation, they were disregarded in the analysis. Instances of codeswitching were also excluded from the analysis. Codeswitching typically occurred when participants switched to their dominant language to reflect out loud on the task or their ability to carry it out, e.g.: "Because... A jakie było pytanie?" (Polish child \#13).

For the classification of errors, we adopted James' (2013) “Target modification taxonomy", which is a well-established and widely used classification system for errors. ${ }^{2}$ His taxonomy evidences five ways in which the learner's L2 production deviates from standard native speaker output, in that the learner can omit an item or add an unnecessary one, form an item incorrectly, put items in an incorrect sequence, or combine two or more of those errors.

Independently of this taxonomy, all errors were identified as being either WLbased of SL-based, according to the examiners' judgment. Unfortunately, no generally accepted and well-known criteria exist for classifying errors into crosslinguistic or not. Most of the recent studies which provide percentages of L1-induced errors in ESL production do not provide any information on the classification criteria used (e.g. Lee 2001; Sarfraz 2011; Subzalipour 2012), while some refer to the very general framework put forward by Richards (1971) (e.g. Abisamra 2003; Falhasiri et al. 2011;

After strong criticism against weaknesses in error classification in early error analysis studies, better classification methods emerged. Dulay, Burt, Krashen (1982) suggested a taxonomy of errors called "Surface structure taxonomy" (SST), consisting of four categories: (1) Omission, (2) Addition, (3) Misformation, and (4) Misordering. James (2013) suggests replacing the label addition by overinclusion, misformation by misselection, and adding a fifth category to the SST: (5) Blends, and renaming the taxonomy "Target modification taxonomy" (TMT). 
Sawalmeh 2013), which is combined with the researcher's own judgment. We based our judgment on the likelihood of an error being caused by the SL. For example, an error which can be clearly classified as not likely to be influenced by the SL is the use of eated instead of ate (Polish child \#13). A possible criterion for such categorization is to verify if that form is attested in studies of monolingual first language acquisition, in which case they are likely to be developmental in nature, or at least not due to influence from the L1 (Simoiu 2014; Montrul 2015). It is the case for this example: monolingual children are known to overgeneralize regular past tense forms (Maslen et al. 2004; De Zeeuw, Schreuder, Verhoeven 2013). An example of an error extremely likely to have been influenced by the SL is "the water exploses" instead of "the water explodes" (French child \#17). In this case, the French form is used (explose) with an English inflection.

Between these two categories (of items highly likely to be L1-induced, and very unlikely to be L1-induced) there remain errors which raise doubts. ${ }^{3}$ For such doubtful cases, we carefully considered the patterns of errors in the two dominant languages as well as whether the form is attested in monolingual L1 acquisition. The final classification was made on the basis of these considerations.

\section{Results}

\subsection{Comparing error rates across groups}

A total of 819 errors in our participants' elicited speech were found and compiled. To make sure our two language groups were comparable in terms of their error production, we measured error density by dividing the number of errors made by each participant by the total number of words he or she produced. This operation yielded a rounded percentage of errors of $7 \%$ for the French-dominant children, and of $5 \%$ for the Polish-dominant ones. With an alpha value set at.05, the difference between means the two groups is considered nonsignificant $(t=1.38 ; \mathrm{p}=.09)$.

\subsection{Comparing error profiles across groups}

We first classified the errors along the five above-mentioned categories from James' (2013) taxonomy. The classification is summarized in Table 1.

The two main types of errors that our participants made were overinclusion errors (mainly by over-regularizing an English rule) and selection errors (mostly wrong word categories or wrong verb tenses). Table 1 also shows that the two subgroups present comparable error profiles, which is further evidenced when displayed in the form of a histogram (see Figure 1).

3 An example of a doubtful case could be a French child saying "the duck listen his mom" (P10). At first, the absence of the preposition could be attributed to the L2, by analogy with "hears his mom". However, a look at the French equivalent shows that no preposition is needed after the French verb ("le canard écoute sa maman"). 


\begin{tabular}{lcccccc} 
Group & Errors & OMIS (\%) & OVER (\%) & SELC (\%) & ORD (\%) & MIX (\%) \\
\hline $\begin{array}{l}\text { French } \\
(\mathrm{n}=44)\end{array}$ & 697 & $31(4 \%)$ & $298(43 \%)$ & $237(34 \%)$ & $30(4 \%)$ & $101(14 \%)$ \\
$\begin{array}{l}\text { Polish } \\
(\mathrm{n}=16)\end{array}$ & 122 & $10(8 \%)$ & $33(27 \%)$ & $59(48 \%)$ & $4(3 \%)$ & $16(13 \%)$ \\
$\begin{array}{l}\text { Total } \\
(\mathrm{N}=60)\end{array}$ & 819 & $41(5 \%)$ & $331(40 \%)$ & $296(36 \%)$ & $34(4 \%)$ & $117(14 \%)$
\end{tabular}

OMIS = Omission OVER $=$ Overinclusion $;$ SELC $=$ Misselection $;$ ORD $=$ Misorder ing; MIX = Blends.

Table 1. Types of errors

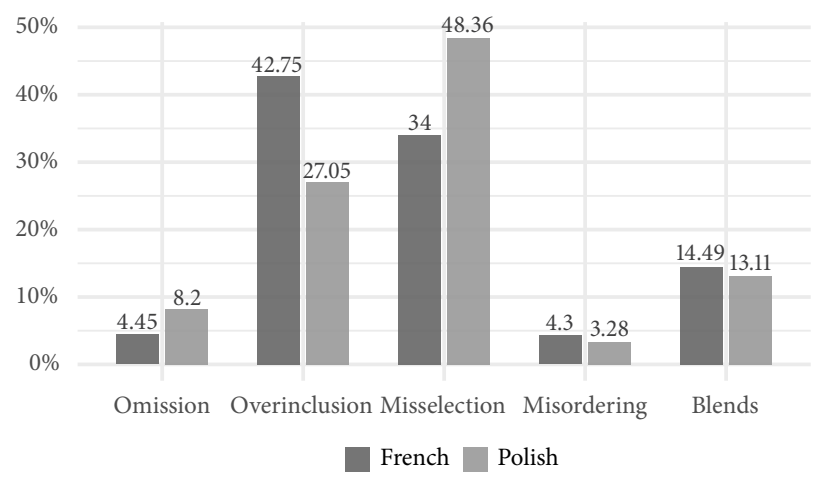

Figure 1: Types of errors: French SL vs Polish SL

The main procedure we chose for exploring crosslinguistic influence was to distinguish between errors that are attributable to the SL and those that are not. The results are presented in Table 2.

\begin{tabular}{lcrcrc} 
Group & Errors & SL influenced & $\%$ & Not SL influenced & $\%$ \\
\hline French $(\mathrm{n}=44)$ & 697 & 158 & $23 \%$ & 539 & $77 \%$ \\
Polish $(\mathrm{n}=16)$ & 122 & 21 & $17 \%$ & 101 & $83 \%$ \\
Total $(\mathrm{N}=60)$ & 819 & 179 & $22 \%$ & 640 & $78 \%$
\end{tabular}

Table 2. Errors and SL influence

As Table 2 shows, both SL groups show comparable error profiles, with roughly one fourth of all errors attributable to crosslinguistic influence, which means that most English errors appear to stem from English itself. The French-SL group shows 
a tendency to produce more crosslinguistic errors (23\% vs. $17 \%$ ). The percentages obtained for both groups are statistically equivalent $(\mathrm{z}=1.35 ; \mathrm{p}=0.18)$.

The next two tables will present the major types of errors made in each of the two categories, in raw figures and in percentages, along with examples of such errors compiled from our corpus. Table 3 covers errors that are not attributed to the SL.

\begin{tabular}{|c|c|c|c|c|c|}
\hline Error type & \multicolumn{2}{|c|}{ French } & \multicolumn{2}{|c|}{ Polish } & Examples \\
\hline \multicolumn{6}{|l|}{ Verb-related } \\
\hline Third person $-s$ missing & 286 & $53 \%$ & 36 & $36 \%$ & $\begin{array}{l}\text { He want (F23) } \\
\text { the worm go (P8) }\end{array}$ \\
\hline Present tense instead of past & 94 & $17 \%$ & 26 & $26 \%$ & $\begin{array}{l}\text { so he fall (F4) } \\
\text { the cat eat the bird (P8) } \\
\text { saw a bird and then go } \\
\text { (P8) }\end{array}$ \\
\hline Other verb-related errors ${ }^{\star}$ & 48 & $9 \%$ & 18 & $18 \%$ & $\begin{array}{l}\text { he tooked it (F41) } \\
\text { he runned (F41) } \\
\text { it's go (F36) }\end{array}$ \\
\hline Total verb-related & 428 & $79 \%$ & 82 & $81 \%$ & \\
\hline Plural $-s$ missing & 6 & $1 \%$ & 0 & $0 \%$ & $\begin{array}{l}\text { A family of bird (F23) } \\
\text { four baby (F26) }\end{array}$ \\
\hline Other non-verb related ${ }^{* *}$ & 105 & $19 \%$ & 19 & $19 \%$ & $\begin{array}{l}\text { catch it with their hand } \\
\text { [=paw] (F30) Just he } \\
\text { comes back (F37) her } \\
\text { mother grounds him } \\
\text { (F43) he jumped to the } \\
\text { river (F46) The Garfield } \\
\text { (P11) }\end{array}$ \\
\hline
\end{tabular}

\section{Total}

$539 \quad 100 \% \quad 101 \quad 100 \%$

* e.g.: double marking of past tense; regularized past; missing copula, missing -ing suffix, unnecessary -ing suffix added, missing "to"

** e.g.: lexical (wrong word), distorted word forms, wrong pronouns, omissions (e.g. missing articles)

Table 3. Intralinguistic errors

Table 4 shows the nature of the errors observed in our participants' speech that were considered to be caused by their SL. As with the previous table, we provide representative errors from our corpus.

Perhaps unsurprisingly, most of the crosslinguistic errors are due to the word order being "borrowed" from the dominant language. A striking feature of the data is that a large number of errors for both SL groups involve prepositions. There is also 


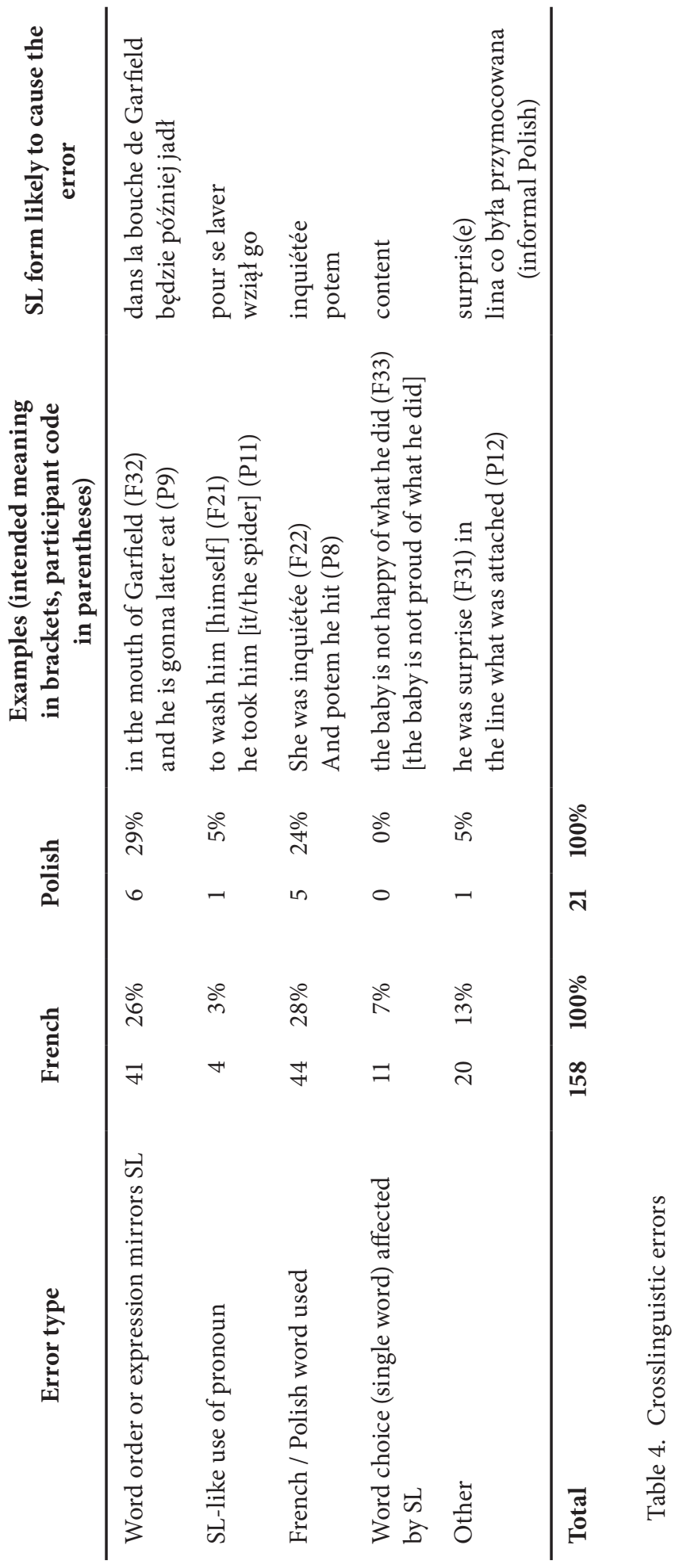


a high number of instances where single lexical items from French and Polish are used in English sentences. An interesting difference between the two language groups can be observed here. Namely, the dominant-language words which are incorporated into the English-language output of our participants are sometimes inflected by the French-dominant children according to the rules of English (e.g.: the water exploses; he was espioning), whereas this never happens in the speech production of the Polish-speaking children.

\section{Discussion}

The most important finding emerging from our study is the fact that crosslinguistic influence affects the WL. This observation goes against the prediction that BFLA should be characterized by little or no crosslinguistic influence: while ESLA children show morphosyntactic influence from their first language, BFLA children tend not to (e.g, De Houwer 2009). This finding could be considered in the light of the quantity of input. Our study did not provide an exact quantification of the WL input received by the participants (if indeed such a quantification is at all possible). The idea of a minimal amount of input needed for language to develop goes back to Noam Chomsky, even though this "minimal input" has not been quantified. We know for sure that children of deaf parents acquire language given a minimal input of 5-10 hours per week of normal spoken language (see Schiff-Myers 1988). If our BFLA children were below that threshold for English input, there are reasons to believe that this language will show evident weaknesses. As Meisel (2007) points out, investigations of cases of incomplete acquisition of grammatical knowledge have focused on maturational constraints. However, if certain phenomena such as nontarget-like forms in the speech of simultaneous bilinguals are considered, he argues, this may be "an indicator of an additional type of constraint on the acquisition device", namely the amount of input. This suggests that "exposure to the primary linguistic data must not only happen during the appropriate developmental phases but it must also reach a certain threshold" (Meisel 2007: 496).

Some features of the dataset suggest that the perceived language distance may play a role in the extent and character of crosslinguistic influence. Firstly, there are more crosslinguistic errors in the speech production of the Canadian participants (even though this observation needs to be treated with caution, the difference not being statistically significant). Secondly, French-speaking children are willing to merge lexical items from French with the inflections of English, which is something the Polish-speaking children never do. In this case, the perceived language distance could be affecting the way in which they use the stronger language for lexical gapfilling: the French-dominants proceed to inflect the French words with English grammar rules as if they were perfectly good English words, whereas for the Polishdominant children the Polish words remain unaffected by English syntax. This is an interesting case of hypothesis forming: perceived language proximity makes children hypothesize whether or not the word in their stronger language is likely to 
be shared with English. This strategy often leads to positive transfer; older children who speak-French commonly venture French words successfully in spontaneous English, given the considerable overlap between the languages.

Perhaps the most interesting observation that emerges from our data is the fact that errors normally perceived as WL-based (and classified as such in our data) might in fact be affected by crosslinguistic influence. The best example is that of the most recurrent error found in our corpus: the missing third-person $-s$. The absence of the third person $-s$ is usually considered to be developmental, and thus not due to crosslinguistic transfer. This morpheme appears relatively late in monolingual acquisition, being an exception that undergoes pressure from all the other regular endings (Dušková 1969; Brown 1973). ${ }^{4}$ However, there are also good reasons for considering it a crosslinguistic error, since in French almost all the verbs have identical phonological forms for all three persons in the singular. A French speaker does not expect the third-person verb ending to be different from the other forms. Speakers of an inflected language like Polish, on the contrary, will expect verb endings to mark the person. Thus the fact that this error in English is so common among our French-speaking participants, and much less common among our Polish-speaking participants, raises the possibility that the absence of a third-person marking in French makes the French-dominant bilingual children less likely to think it is salient, and therefore the acquisition of this feature in English might be delayed. ${ }^{5}$ To that effect, if we considered the absence of the third person "s" as SL-induced for the speakers of French (who do not expect the third person to be marked), then the percentage of SL-induced errors would almost triple for that group, rising from $23 \%$ to $64 \%$.

Another noteworthy feature of our data is that a large number of errors for both SL groups involve prepositions. This is in keeping with the findings of some previous studies, which found prepositions to be prone to crosslinguistic transfer (cf. Matras 2009). However, the errors involving prepositions in our data, when considered collectively, reveal an interesting possibility. The errors in our database were classified as SL-induced or not on an individual basis. However, a comparison of general tendencies between the two SL groups provides further proof that the underlying reason for some errors is indeed crosslinguistic. For example, to say that the mother duck was screaming at her baby, the French dominant children tended to use the preposition "after" (French: "elle crie après lui") while the Polish dominant children tended to use the preposition "on" (Polish: "nakrzyczała na niego"). Yet there

4 Alternative explanations to this late acquisition can also be suggested in terms of Pienemann's (1998) learnability/teachability theory, by invoking the inability to perform the requisite processing operations. It would also be possible to discuss it in terms of the distinction between explicit and implicit knowledge (Ellis 2009).

5 Admittedly, there is obvious impact of our instrument on the participants' output. The third person $-s$ is clearly overrepresented in our data due to the fact that participants were required to tell stories rather than talk about themselves. This explains why we hardly have any verbs in the first person in our data, despite the fact that children tend to use the first person (Morgenstern 2006), probably because of its positive effect on learning and retention (Hartlep, Forsyth 2000). However, that does not change the fact that the missing $-s$ is a much more predominant error in the French speakers' output than in that of the Polish participants. 
is a difference in the proportion of such prepositions-related errors in the overall number of non-target forms: in the French-dominant children, prepositions represent $21 \%$ of the errors in English; in the Polish-dominant children, they represent $43 \%$ of the errors. Those proportions are consistent with the degree of similarity between the prepositions of the languages in presence: the French prepositional system is very close to the English one, while the Polish system is much less similar.

An issue that was raised decades ago (Dulay, Burt 1974) is that it may be impossible to determine whether an error is caused by crosslinguistic influence or is due to rules of the language being spoken. For example, in our corpus, there were several instances such as "the bird go attack" instead of "the bird goes to attack" (French child \#25). Some researchers would argue that the absence of "to" is due to crosslinguistic influence, given its absence in the child's dominant language (French: "l'oiseau va attaquer"). However, one could invoke the existence of similar structures in English with the imperative, which is overrepresented in child-directed speech: come play, go see, etc. (Cameron-Faulkner, Lieven, Tomasello 2003; Finegan 2015). However, an alternative explanation could combine both factors: maybe that absence of to was noticed by the child in some English structures, which strengthens his initial assumption based on his $\mathrm{L} 1$ that the to is not needed. This mutual dynamic between both factors would increase the likelihood of making errors, which is reminiscent of Andersen's transfer-to-somewhere principle (Andersen 1983).

\section{Conclusions}

Our results suggest that the weaker language of bilingual children shows substantial crosslinguistic influence from the stronger language. While the majority of non-targetlike forms in the children's output resemble those in monolingual first language acquisition (ca. $80 \%$ ), the remaining $20 \%$ seem to be SL-induced. This goes against the general expectation that simultaneous bilingual language acquisition should be characterized by relatively little crosslinguistic influence. At the same time, this percentage is about half of what is typically found in adult ESL learners. Thus, in the light of our study, it looks like apart from the age of onset, an important factor may be the amount of input. Further studies are needed to investigate the relationship between the amount of input and the extent of cross-linguistic influence in simultaneous bilinguals.

Additionally, our findings suggest that the number of errors caused by the SL may in reality be even higher, even though this is not apparent when errors are classified individually, or for a single SL group. By involving two different SL groups, our study made it possible to observe that certain errors not normally considered to be crosslinguistic in nature, may in fact be at least to some extent caused by interference from the SL, because of the different patterns of distribution of these errors in the two language groups (as we have illustrated with the case of the missing third person $-s$ ). Finally, our findings raise the possibility that language distance (actual or perceived) may play a role in the nature and amount of crosslinguistic influence in BFLA. 


\section{References}

Abisamra N. 2003. An analysis of errors in Arabic speakers' English writing. [http://abisamra03. tripod.com/nada/languageacq-erroranalysis.html].

Andersen R. 1983. Transfer to somewhere. - Gass S., Selinker L. (eds.). Language transfer in language learning. Rowley (MA): 177-201.

Argyri E., Sorace A. 2007. Crosslinguistic influence and language dominance in older bilingual children. - Bilingualism: Language and Cognition 10.1: 79-99.

Aronin L., Singleton D. 2012. Multilingualism. Amsterdam.

Bonnesen M. 2009. The status of the "weaker" language in unbalanced French/German bilingual language acquisition. - Bilingualism: Language and Cognition 12.2: 177-192.

Brown R. 1973. A first language: The early stages. Cambridge (MA).

Cameron-Faulkner T., Lieven E., Tomasello M. 2003. A construction based analysis of child directed speech. - Cognitive Science 27: 843-873.

De Houwer A. 2007. Parental language input patterns and children's bilingual use. - Applied Psycholinguistics 8: 411-424.

De Houwer A. 2009. Bilingual first language acquisition. Bristol.

De Zeeuw M., Schreuder R., Verhoeven L. 2013. Processing of regular and irregular pasttense verb forms in first and second language reading acquisition. - Language Learning 63: 740-765.

Döpke S. 1992. One parent, one language: An interactional approach. Amsterdam.

Döpke S. 2000a. On the status of crosslinguistic structures in research on young children growing up with two languages simultaneously. - Döpke S. (ed.). Crosslinguistic structures in simultaneous bilingualism. Amsterdam: 1-10.

Döpke S. 2000b. The interplay between language-specific development and crosslinguistic influence. - Döpke S. (ed.). Crosslinguistic structures in simultaneous bilingualism. Amsterdam: 79-103.

Dulay H., Burt M. 1974. You can't learn without goofing. - Richards J.C. (ed.). Error analysis. London: 95-124.

Dulay M., Burt H., Krashen S. 1982. Language two. New York.

Dunn L.M., Dunn D.M. 2007. Peabody picture vocabulary test. [ $4^{\text {th }}$ edition, $=$ PPVT-4]. Minneapolis (MN).

Dunn L.M., Thériault-Whalen C.M., Dunn D.M. 1993. Échelle de vocabulaire en images Peabody. Toronto.

Duškova L. 1969. On sources of errors in foreign language learning. - International Review of Applied Linguistics. 7: 11-31.

Ellis R. 2009. Implicit and explicit learning, knowledge, and instruction. - Ellis R., Loewen S., Elder C., Erlam R., Philp J., Reinders H. (eds.). Explicit and implicit knowledge in second language learning, testing and teaching. Bristol (UK): 3-25.

Falhasiri M., Tavakoli M., Hasiri F., Mohammadzadeh A.R. 2011. The effectiveness of explicit and implicit corrective feedback on interlanguage and intralingual errors: A case of error analysis of students' compositions. - English Language Teaching 4.3: 252-264.

Finegan E. 2015. Language: Its structure and use. [ $7^{\text {th }}$ edition]. Stamford (CT).

Flores C. 2015. Losing a language in childhood: A longitudinal case study on language attrition. - Journal of Child Language. 42: 562-590.

Foroodi-Nejad F., Paradis J. 2009. Crosslinguistic transfer in the acquisition of compound words in Persian-English bilinguals. - Bilingualism: Language and Cognition 12.4: 411-427.

Francis N. 2011. Imbalances in bilingual development: A key to understanding the faculty of language. - Language Sciences 33.1: 76-89. 
Grosjean F. 2016. The Complementarity Principle and its impact on processing, acquisition, and dominance. - Silva-Corvalán C., Treffers-Daller J. (eds.). Language dominance in bilinguals: Issues of measurement and operationalization. Cambridge (MA).

Haman E., Fronczyk K., Łuniewska M., Kamykowska J. 2012. Obrazkowy test słownikowy: rozumienie. Gdańsk.

Hartlep K., Forsyth A. 2000. The effect of self-reference on learning and retention. - Teaching of Psychology 27.4: 269-271.

Hulk A. 2000. Non-selective access and activation in child bilingualism: The syntax. - Döpke S. (ed.). Crosslinguistic structures in simultaneous bilingualism. Amsterdam: 75-104.

Hulk A., Müller N. 2000. Bilingual first language acquisition at the interface between syntax and pragmatics. - Bilingualism: Language and Cognition 3.3: 227-244.

James C. 2013. Errors in language learning and use: Exploring error analysis. New York.

Jarvis S., Pavlenko A. 2007. Crosslinguistic influence in language and cognition. New York.

Kellerman E. 1983. Now you see it, now you don't. - Gass S., Selinker L. (eds.). Language transfer in language learning. Rowley (MA): 112-134.

Kupisch J. 2007. Determiners in bilingual German-Italian children: What they tell us about the relation between language influence and language dominance. - Bilingualism: Language and Cognition 10.1: 57-78.

Lanza E. 1997. Language mixing in infant bilingualism: A sociolinguistic perspective. Oxford.

LeBlanc R., Séguin H. 1995. Les congénères homographes et parographes anglais-français. Courchêne R., Burger S., Cornaire C., LeBlanc R., Paribakht T.S., Séguin H. (eds.). Twentyfive years of second language teaching at the University of Ottawa. Ottawa: 69-91.

Lee E.P. 2001. Error analysis on medical students' writing. [http://oldrussian.ru/error-analysison-medical-students-writing.html; consulted March 22, 2018].

Leśniewska J., Pichette F. 2013. Syntactic and collocational aspects of bilingual children's weaker language. [Conference ISTAL21, Thessaloniki, Greece, April].

Leśniewska J., Witalisz E. 2013. Crosslinguistic influence and bilingual children's weaker language. - Pawlak M., Aronin L. (eds.). Essential topics in applied linguistics and multilingualism: Second language learning and teaching. Berlin: 225-233.

Maslen R., Theakston A., Lieven E., Tomasello M. 2004. A dense corpus study of past tense and plural overregularization in English. - Journal of Speech, Language \& Hearing Research 47: 1319-1333.

Matras Y. 2009. Language contact. Cambridge.

Meisel J. 2007. The weaker language in early child bilingualism: Acquiring a first language as a second language? - Applied Psycholinguistics 28: 495-514.

Montrul S. 2015. The acquisition of heritage languages. Cambridge.

Morgenstern A. 2006. Quand l'enfant se désigne comme sujet. - L'information grammaticale 110: 31-37.

Nicoladis E. 2016. Measuring language dominance in bilingual children: Implications for crosslinguistic influence. - Silva-Corvalán C., Treffers-Daller J. (eds.). Language dominance in bilinguals: Issues of measurement and operationalization. Cambridge: 219-234.

Nicoladis E., Genesee F. 1997. The role of parental input and language dominance in bilingual children's code-mixing. - Hughes E., Hughes M., Greenhill A. (eds.). Proceedings of the 21st Annual Boston University Conference on Language Development. Somerville (MA): 422-432.

Otwinowska-Kasztelanic A. 2010. Language awareness in using cognate vocabulary: The case of Polish advanced students of English in the light of the theory of affordances. - Arabski J., Wojtaszek A. (eds.). Second language acquisition studies in neurolinguistic and psycholinguistic perspective. Bristol: 175-190. 
Paradis J., Navarro S. 2003. Subject realization and crosslinguistic interference in the bilingual acquisition of Spanish and English: What is the role of input? - Journal of Child Language 30: 371-393.

Pichette F., Leśniewska J. 2018. Percentage of L1-based errors in ESL: An update on Ellis (1985). - International Journal of Language Studies 12: 1-16.

Pienemann M. 1998. Language processing and second language development: Processability theory. Amsterdam.

Richards J.C. 1971. A non-contrastive approach to error analysis. - English Language Teaching 25.3: 204-219.

Ringbom H. 1987. The role of the first language in foreign language learning. Clevedon (UK). Sarfraz S. 2011. Error analysis of the written English essays of Pakistani undergraduate students: A case study. - Asian Transactions on Basic \& Applied Sciences 1.3: 29-51.

Sawalmeh M.H.M. 2013. Error analysis of written English essays: The case of students of the preparatory year program in Saudi Arabia. - English for Specific Purposes World 40.14: 1-17.

Schiff-Myers N. 1988. Hearing children of deaf parents. - Bishop D., Mogford K. (eds.). Language development in exceptional circumstances. Edinburgh: 47-61.

Silva-Corvalán C. 2014. Bilingual language acquisition: Spanish and English in the first six years. Cambridge (MA).

Simoiu A. 2014. The split IP parameter in second language learning. Newcastle.

Subzalipour B. 2012. Error analysis on students' Persian-English translation. [http://www. ajssh.leena-luna.co.jp/AJSSHPDFs/Vol.1(4)/AJSSH2012(1.4-08).pdf].

Treffers-Daller J., Korybski T. 2016. Using lexical diversity measures to operationalise language dominance in bilinguals. - Silva-Corvalán C., Treffers-Daller J. (eds.). Language dominance in bilinguals: Issues of measurement and operationalization. Cambridge: 106-133.

Unsworth S. 2016. Amount of exposure as a proxy for dominance in bilingual language acquisition. - Silva-Corvalán C., Treffers-Daller J. (eds.). Language dominance in bilinguals: Issues of measurement and operationalization. Cambridge (MA): 156-173.

Yip V., Matthews S. 2000. Syntactic transfer in a Cantonese-English bilingual child. - Bilingualism: Language and Cognition 3.3: 193-208.

Yip V., Matthews S. 2007. The bilingual child: Early development and language contact. Cambridge. 